\title{
The Influence of Light on Mood*
}

\author{
Tonello G. L., Sandoval J. D. \\ Instituto de Investigación en Luz, Ambiente y Visión \\ UNT/CONICET, Tucumán, República Argentina
}

\author{
Nuñez C. G., Duca G. L., Piro Magariños M. B. \\ Universidad Nacional de Tucumán, Tucumán, República
}

Argentina

\begin{abstract}
Light is the most important environmental signal for the mammalian circadian system, and is detected exclusively by the eyes via specialized ganglion cell photoreceptors. Cycles of light and darkness relayed by the retina entrain suprachiasmatic nuclei neural activity, which in turn entrains the rhythmic production and secretion of melatonin from the pineal gland. Deficiencies on the daily and seasonal pattern of melatonin secretion seem to be one of the main causes of mood disorders. Since several studies confirmed that depressed patients show low concentrations of melatonin at night and that this could be an individual trait marker, the objective of this study was to test a hypothesis proposed by Stone to the lighting community in 1999 related to possible associations between glare sensitivity, melatonin response and depression. In the present research report, significant correlations were found between winter depression and melatonin production with age. On the other hand, sensitivity to glare significantly correlated with melatonin production during winter. Taken together, the results lend support for more investigation on these associations.
\end{abstract}

Keywords: light, melatonin, mood, vulnerability

\section{Introduction}

Environmental light is the main stimulus responsible for the entrainment of circadian system. The mammalian eye has dual roles in detecting optical radiation for both image-formation and for circadian, neuroendocrine, and neurobehavioral responses. This includes acute effects such as suppressing pineal melatonin production, elevating morning cortisol production, increasing subjective alertness, enhancing psychomotor performance, changing brain activation patterns to a more alert state, elevating heart rate, increasing core body temperature, activating pupil constriction, and even stimulating circadian clock gene

\footnotetext{
*Acknowledgements: The study was supported by Consejo Nacional de Investigaciones Científicas y Técnicas (CONICET), Argentina. Many persons have contributed in different ways to this research. Especially with regard to melatonin measurements, Dr Lennart Wetterberg provided valuable advice on the procedure. We also thank Mónica Delgado (INSIBIO) and Hugo and Nancy Borsetti (INBIAL) for their commitment during the samples analysis, Clemente Paz Filgueira and Roberto Sanchez (ILAV) for the glare measurements, and Thorbjörn Laike (Lund University) for his help on statistical issues. The authors gratefully acknowledge Wout Van Bommel and Marianne Küller, for their comments upon de manuscript.

Tonello G. L., Departamento de Luminotecnia, Luz y Visión (DLLyV), Facultad de Ciencias Exactas y Tecnología, Universidad Nacional de Tucumán (UNT)/Instituto de Investigación en Luz, Ambiente y Visión (ILAV), Consejo Nacional de Investigaciones Científicas y Técnicas (CONICET).

Sandoval J. D., Departamento de Luminotecnia, Luz y Visión (DLLyV), Facultad de Ciencias Exactas y Tecnología, Universidad Nacional de Tucumán (UNT)/Instituto de Investigación en Luz, Ambiente y Visión (ILAV), Consejo Nacional de Investigaciones Científicas y Técnicas (CONICET).

Nuñez C. G., Cátedra de Bioquímica, Facultad de Medicina, Universidad Nacional de Tucumán (UNT).

Duca G. L., Cátedra de Bioquímica, Facultad de Medicina, Universidad Nacional de Tucumán (UNT).

Piro Magariños M. B., Cátedra de Bioquímica, Facultad de Medicina, Universidad Nacional de Tucumán (UNT).
} 
expression (DiLaura, Houser, Mistrick, \& Steffy, 2011). Circulating melatonin is produced and secreted mostly at night by the pineal gland. Its secretion is proportional to the duration of darkness, and it thus acts as a chemical code of scotophase duration. Melatonin secretion responds to signals from the central pacemaker located in the suprachiasmatic nuclei and in that the timing of the melatonin rhythm indicates the status of the clock, both in terms of phase and amplitude (Fideleff et al., 2006).

Light can have an acute suppressive effect on high levels of melatonin during the night. A specific bandwidth of blue light, from $446-477 \mathrm{~nm}$ and peaking at $464 \mathrm{~nm}$ was determined for the "action spectrum" or bandwidth responsible for suppressing melatonin (Brainard, Hanifin, Greeson, Byrne, \& Glickman, 2001; Brainard et al., 2008). Melanopsin, a photopigment expressed in a subset of retinal ganglion cells (with maximum peak sensitivity in this blue light range), mediates most of the non-visual effects of light on behavior (Provencio, Rodriguez, Jiang, Hayes, Moreira, \& Rollag, 2000; Provencio, Rollag, \& Castrucci, 2002; Berson, Dunn, \& Takao, 2002; Stephenson, Schroder, Bertschy, \& Bourgin, 2012).

A number of experimental studies have concluded that there are lower concentrations of melatonin at night in depressed patients. Lewy et al. (Lewy, Wehr, Goodwin, Newsome, \& Rosenthal, 1981; Lewy, Sack, Singer, White, \& Hoban, 1988) showed that depressed patients were more sensitive to the suppression of melatonin by light, and further demonstrated considerable differences in sensitivity to melatonin suppression between manic depressive patients and normal controls. Low melatonin and elevated cortisol levels have typically been reported during depression. The evidence that the converse is true during mania has been less well documented (Kennedy, Tighe, McVey, \& Brown, 1998). Levels and also timing of melatonin secretion are altered in patients with bipolar affective disorder and SAD (seasonal affective disorder) sufferers. According to Srinivasan et al, (2006), melatonin can be both a "state marker" and a "trait marker" of mood disorders. Measurements of melatonin either in saliva or plasma, or of its main metabolite 6-sulfatoxymelatonin in urine, have documented significant alterations in melatonin secretion in depressive patients during the acute phase of illness. Melatonin administered orally in pharmacological quantities, significantly decreased self-reported alertness and increased sleepiness as measured by standardized mood questionnaires. Although the effects were brief, melatonin also affected performance and slowing choice-reaction time and it has sedative like-properties (Harris et al., 1984).

According to Wetterberg et al. (1999a; Wetterberg, Bratlid, Von Knorring, Eberhard, \& Yuwiler, 1999b), melatonin was found to vary inversely with age and may represent the declining capacity of the pinealocytes or/and of the enzymes responsible for melatonin synthesis to produce the genetically programmed quantity of melatonin over the years. They found that females as a whole, has higher melatonin values than males. Leger Laudon, and Zisapel (2004) found that low nocturnal melatonin production $(9.0 \pm 8.3 \mu \mathrm{g}$ per night, mean 6-sulfatoxymelatonin) is associated with insomnia in patients aged 55 years or older, and identified patients who are somewhat more likely to respond to melatonin replacement. The reason for this decline of hormonal secretion with age is unknown and not correlated with the size of the pineal organ. But it is well established that melatonin secretion is enormously different between individuals ("low secretor" versus "high secretor"), which could be a reason why not all populations studied reveal such age differences (Münch et al., 2005). A study conducted by Wade et al. (2010) found that low melatonin excretion level regardless of age is not useful in predicting the response to PRM (Prolonged release melatonin) in insomnia. The strong finding of age related efficacy may reflect within patient reduction in melatonin levels which is masked in the younger age groups by the wide variability in normal levels. In healthy adults, the nocturnal melatonin production rate is normally 10 to $80 \mu \mathrm{g} /$ night and urinary excretion of the main melatonin metabolite, 6 -sulphatoxymelatonin (6-SMT) is 8 to 
$56 \mu \mathrm{g} /$ night but with wide variability. Thus, low endogenous melatonin in adults was defined as urinary excretion of the major melatonin metabolite of $<8 \mu \mathrm{g}$ 6-SMT per night.

A review from Turner, Van Someren, and Mainster (2009) explains how chronic chronodisruption may increase the risks of insomnia, depression, cognitive impairment, dementia, inflammation, obesity, metabolic syndrome, cardiovascular disease, and premature mortality. Interactions are complex, but light deficiency may be a common causative factor. Most blind people with no perception of light have either nonentrained or abnormally phased circadian rhythms due to this inability to detect light (Flynn-Evans, Tabandeh, Skene, \& Lockley, 2014).

Short-wave length lights, whose transmittance decreases with age, is important for nonvisual information processing such as circadian rhythms (melatonin, body temperature, sleep/wake rhythms) as well as ocular vision and color perception (Morita, 2011). Thus, the susceptibility to glare increases with advancing years (Schieber 1992). Glare is defined as the sensation produced by luminances within the visual field that are sufficiently greater than the luminance to which the eyes are adapted, which causes annoyance, discomfort, or loss in visual performance and visibility (Rea, 2000). There are two forms of glare that are a matter of the range of luminances simultaneously present in the visual field: Disability glare reduces visibility due to light scattered in the eye, reducing the luminance contrast of the retinal image. On the other hand, discomfort glare occurs when people complain about visual discomfort in the presence of bright light sources, luminaires, or windows (Boyce, 2003; 2011). CSF (the contrast sensitivity function) is strongly affected by the presence of a glaring source within the visual field. The greater is the luminous intensity of the source and the closer of the vision line it is, the greater will be its effect on the CSF. Generally speaking, the capability of the visual system of detecting contrast differences diminishes due to the action of the glaring source; i.e., the glaring source makes the CSF to decrease (Abrohomsson \& Sjosrrand, 1986).

\section{Methods}

\section{Problem}

In 1999, Stone pointed out that "Since supersensitivity to melatonin suppression by light might be an individual trait marker, then this might be related to differences in sensitivity to glare". The same author reported that a number of experimental studies have concluded that there are lower concentrations of melatonin at night in depressed patients.

Since this hypothesis was worth testing, the present study, at the first stage, shows the results of measurements of the three factors involved: glare sensitivity, melatonin production, and symptoms of depression.

\section{Subjects}

Participants were 14 healthy volunteer university members (students, teachers, and administrative staff), six men and eight women, with an age range from 25 to 56. All subjects were medically (clinical and ophthalmological) and psychiatrically screened to exclude somatic or severe mental disease. Informed consent was obtained from all subjects.

\section{Measurements}

Melatonin. Melatonin production was assessed by measuring the nocturnal 12-hr urinary output of the major melatonin metabolite, 6-sulfatoxymelatonin. The cut-off point was set at $12 \mu \mathrm{g} / 12 \mathrm{hs}$ for ages up to 35 years (Wade et al., 2010). 
Urine samples were collected at home one day of December (summer) and July (winter) by all the subjects. Each subject was provided with a plastic bottle where the total volume of urine excreted during 12 hours, between 1900 and 0700 the next day, was accumulated. Inmediately after that, bottles were taken by the participants to a laboratory where aliquots of the total urine of each individual were extracted, frozen, and stored at $-20^{\circ} \mathrm{C}$ until assayed. The test used was the enzyme immunoassay for the quantitative determination of melatonin sulfate in human urine. Most of the circulating melatonin is metabolized in the liver to 6-hydroxymelatonin and subsequently to 6-sulfatoxymelatonin which is excreted into the urine, and correlates highly with the 2 am peak value of serum melatonin. The assay had an analytical sensitivity (limit of detection) of $1.0 \mathrm{ng} / \mathrm{mL}$, and an analytical specifity (cross-reactivity) of other substances tested of $<0.0001 \%$. Melatonin values were expressed as concentration in $\mu \mathrm{g} / 12$ hours nocturnal.

The total urine volume excreted during nocturnal 12 hours and melatonin concentration values, in summer and winter, are presented in Table 1.

Glare. In this study, glare sensitivity was estimated by measuring CSF, with and without glare, by means of different physical and psychophysical techniques. Thus, observers with high sensitivity to glare would be expected to show a noticeable decrease in their CFS under the action of the glaring source.

\section{Experimental Setup for Glare Measurements}

As it was mentioned before, participants were screened to exclude diseases. Specifically for glare measurements, the screening involved cataract information for both eyes as well as their history of visual impairments and surgeries. Besides, before the experiment, each observer performed a standard sight/visual test in order to check their vision was normal, with and without corrective lenses.

To assess glare sensitivity, the CSV1000 equipment was used. This device tests a combination of contrast and glare sensitivity and it is widely accepted for the evaluation of contrast sensitivity, low contrast acuity and glare sensitivity. CSF evaluation was performed with the normalized version of the CSV-1000E Chart (VectorVision, Dayton, OH), proposed by Boxer and Krueger (1998). Then, contrast sensitivity determines the lowest contrast level which can be detected by a person for a given size target (see Table 2).

These measurements were reinforced by means of two additional methods: the C-QUANT and the OQAS (optical quality analysis system) apparatus. The Cataract-Quantifier or C-Quant measures in an accurate and objective way the amount of straylight (light scattering in the eye media) in a patient's eye. It is based on the "compensation comparison" method (Van Rijn et al., 2000; Franssen, Coppens, \& Van den Berg, 2006). On the other hand, OQAS is based on the double-pass technique and provides an objective measurement of the optical quality of the eye. A punctual light source is imaged on the retina. The size and the shape of the light spot (light passes twice through ocular media) are analysed by OQAS. Its images contain all the information about the optical quality of the eye including all the higher order aberrations and scattered light. These higher order aberrations have an important impact on the amount of scattered light into the eye and inform us about its conditions. Then, OQAS is capable to give us objective measurements sharply related to glare sensitivity (see Table 3).

\section{Mood}

To assess mood, the Beck Depression Inventory II (Beck, Steer, \& Brown, 2006) was administered to the sample for two consecutive years, including winter and summer seasons. The BDI-II is a multiple-choice self-report inventory containing 21 questions $(\alpha=0.91)$, each answer being scored on a scale value of 0 to 3 . 
Each item is a list of four statements arranged in increasing severity about a particular symptom of depression, in alignment with DSM-IV criteria; higher total scores indicate more severe depressive symptoms. The questionnaire is designed for individuals aged 13 and over, and it can be used in clinical and normal patients.

The 21 items comprise the following symptoms: Sadness, Pessimism, Failure, Loss of Pleasure, Guilty Feelings, Punishment Feelings, Self-Dislike, Self-Criticalness, Suicidal Thoughts, Crying, Agitation, Loss of Interest, Indecisiveness, Worthlessness, Loss of Energy, Changes in Sleep Pattern, Irritability, Changes in Appetite, Concentration Difficulty, Fatigue and Loss of Interest in Sex.

Items number 9 suicidal thoughts and number 21 loss of interest in sex were canceled for this study. Participants were asked to rate how they have been feeling for the past two weeks (see Table 4).

\section{Statistics}

Three indices were created based on the tested factors, namely melatonin $(1=$ High producer; $2=$ Low producer), glare ( $1=$ Insensitive to glare; $2=$ Sensitive to glare), and depression $(1=$ No depressed; $2=$ Depressed). The cut-off point for the first index was set at $12 \mu \mathrm{g} / 12 \mathrm{hs}$ for ages up to 35 years. For the second index, values of the difference equal to or greater than 2 indicated sensitivity to glare. The interval for the last index was set at 0-13 for "No depression" and 14-28 for "Depression".

Indices and raw data were treated by means of non parametric correlations Kendall's tau_b and Spearman's rho. Calculations were carried out with SPSS 15.0.

\section{Results}

Melatonin production was assessed by measuring the nocturnal 12-hr urinary output of the predominat melatonin metabolite 6-sulfatoxymelatonin. In Table 1 can be observed higher values in summer than in winter.

Table 1

Participants, 6-sulfatoxymelaton in Concentration in $\mu \mathrm{g} / \mathrm{hr}$ and Total Urine Volumes in $\mathrm{ml}$ (for Winter and Summer), Age, and Sex

\begin{tabular}{|c|c|c|c|c|c|c|}
\hline \multirow{2}{*}{ Participant } & 6-SMT $\mu \mathrm{g} / 12$ hs nocturnal & \multirow{2}{*}{ Uvol (ml) } & 6-SMT $\mu \mathrm{g} / 12$ hs nocturnal & \multirow[t]{2}{*}{ Uvol (ml) } & \multicolumn{2}{|c|}{ Age (Years) Sex } \\
\hline & Summer & & Winter & & & \\
\hline 1 & 33.15 & 650 & 22 & 580 & 34 & $\mathrm{M}$ \\
\hline 2 & 10.9 & 1,160 & 11.5 & 960 & 56 & $\mathrm{~F}$ \\
\hline 3 & 15.75 & 700 & 11.9 & 660 & 25 & $\mathrm{~F}$ \\
\hline 4 & 3.89 & 560 & 3.1 & 880 & 50 & $\mathrm{~F}$ \\
\hline 5 & 21.7 & 700 & 0.95 & 470 & 38 & $\mathrm{~F}$ \\
\hline 6 & 62.78 & 1,460 & 79.6 & 1,170 & 35 & $\mathrm{~F}$ \\
\hline 7 & 5.59 & 1,140 & 6.15 & 1,230 & 31 & $\mathrm{~F}$ \\
\hline 8 & 57.4 & 820 & 19.6 & 400 & 29 & $\mathrm{~F}$ \\
\hline 9 & 41.2 & 1,030 & 41.05 & 1,080 & 22 & $\mathrm{M}$ \\
\hline 10 & 38.3 & 660 & 17.16 & 660 & 33 & $\mathrm{M}$ \\
\hline 11 & 36.6 & 620 & 16.34 & 760 & 50 & $\mathrm{~F}$ \\
\hline 12 & 18 & 580 & 11.26 & 1,310 & 25 & $\mathrm{M}$ \\
\hline 13 & 10.6 & 800 & 9.8 & 760 & 47 & $\mathrm{M}$ \\
\hline 14 & 49.5 & 630 & 0.95 & 630 & 49 & $\mathrm{M}$ \\
\hline
\end{tabular}

In Table 2 are summarized the results obtained with CSV1000 for glare sensitivity. It was estimated by means of CSF with and without glare, for spatial frequency values of 3, 6, 12, and 18, and for both eyes (right and left, R-L). 
Table 3 was made from the above information, and shows the differences between CSV1000 scores with and without glare, determined for spatial frequency values of $3,6,12$, and 18 . Values of the difference equal to or greater than 2 indicate particular sensitivity to glare.

Table 2

CSF Scores With and Without Glare for All the Participants

\begin{tabular}{|c|c|c|c|c|c|c|c|c|c|c|c|c|c|c|}
\hline \multirow{2}{*}{ Participant } & \multirow{2}{*}{$\begin{array}{l}\text { Visual } \\
\text { acuity }\end{array}$} & \multirow[t]{2}{*}{ EYE } & \multicolumn{5}{|c|}{ Score without glare } & \multicolumn{3}{|c|}{ Score with glare } & \multicolumn{4}{|c|}{ Score with glare, 2 nd set } \\
\hline & & & 3 & 6 & 12 & 18 & 3 & 6 & 12 & 18 & 3 & 6 & 12 & 18 \\
\hline \multirow{2}{*}{1} & 1 & $\mathrm{R}$ & 5 & 5 & 5 & 6 & 4 & 3 & 4 & 5 & 4 & 3 & 4 & 5 \\
\hline & 1 & $\mathrm{~L}$ & 5 & 6 & 4 & 6 & 3 & 5 & 3 & 6 & 3 & 5 & 3 & 6 \\
\hline \multirow{2}{*}{2} & 0.8 & $\mathrm{R}$ & 5 & 5 & 4 & 5 & 6 & 6 & 1 & 6 & 6 & 6 & 1 & 6 \\
\hline & 1 & $\mathrm{~L}$ & 6 & 7 & 6 & 6 & 6 & 6 & 6 & 6 & 6 & 6 & 6 & 6 \\
\hline \multirow{2}{*}{3} & 1 & $\mathrm{R}$ & 7 & 4 & 4 & 4 & 2 & 3 & 3 & 4 & 2 & 3 & 3 & 4 \\
\hline & 1 & $\mathrm{~L}$ & 4 & 4 & 4 & 4 & 2 & 3 & 4 & 4 & 2 & 3 & 4 & 4 \\
\hline \multirow{2}{*}{4} & 0.6 & $\mathrm{R}$ & 3 & 0 & 0 & 0 & 0 & 0 & 0 & 0 & 0 & 0 & 0 & 0 \\
\hline & 1 & $\mathrm{~L}$ & 4 & 5 & 3 & 6 & 4 & 4 & 4 & 6 & 4 & 4 & 4 & 6 \\
\hline \multirow{2}{*}{5} & 0.8 & $\mathrm{R}$ & 4 & 3 & 5 & 3 & 4 & 3 & 1 & 2 & 4 & 3 & 1 & 2 \\
\hline & 0.8 & $\mathrm{~L}$ & 6 & 3 & 4 & 4 & 5 & 3 & 4 & 4 & 5 & 3 & 4 & 4 \\
\hline \multirow{2}{*}{6} & 1 & $\mathrm{R}$ & 4 & 5 & 4 & 5 & 4 & 4 & 3 & 5 & 4 & 4 & 3 & 5 \\
\hline & 1 & $\mathrm{~L}$ & 5 & 2 & 5 & 5 & 4 & 4 & 5 & 5 & 4 & 4 & 5 & 5 \\
\hline \multirow{2}{*}{7} & 1 & $\mathrm{R}$ & 6 & 5 & 5 & 6 & 5 & 5 & 4 & 5 & 5 & 5 & 4 & 5 \\
\hline & 1 & $\mathrm{~L}$ & 5 & 5 & 5 & 5 & 5 & 5 & 5 & 4 & 5 & 5 & 5 & 4 \\
\hline \multirow{2}{*}{8} & 1 & $\mathrm{R}$ & 5 & 6 & 5 & 7 & 4 & 5 & 6 & 7 & 4 & 5 & 6 & 7 \\
\hline & 1 & $\mathrm{~L}$ & 5 & 5 & 6 & 6 & 6 & 5 & 6 & 7 & 6 & 5 & 6 & 7 \\
\hline \multirow{2}{*}{9} & 1 & $\mathrm{R}$ & 5 & 5 & 1 & 4 & 5 & 6 & 2 & 3 & 5 & 6 & 2 & 3 \\
\hline & 0.9 & $\mathrm{~L}$ & 5 & 6 & 5 & 4 & 5 & 6 & 6 & 6 & 5 & 6 & 6 & 6 \\
\hline \multirow{2}{*}{10} & 1 & $\mathrm{R}$ & 6 & 7 & 6 & 7 & 4 & 5 & 5 & 5 & 4 & 5 & 5 & 5 \\
\hline & 1 & $\mathrm{~L}$ & 6 & 7 & 7 & 7 & 4 & 5 & 6 & 7 & 4 & 5 & 6 & 7 \\
\hline \multirow{2}{*}{11} & 0.9 & $\mathrm{R}$ & 4 & 5 & 4 & 4 & 4 & 3 & 5 & 5 & 4 & 3 & 5 & 5 \\
\hline & 0.9 & $\mathrm{~L}$ & 4 & 6 & 4 & 4 & 5 & 3 & 2 & 4 & 5 & 3 & 2 & 4 \\
\hline \multirow{2}{*}{12} & 1 & $\mathrm{R}$ & 6 & 5 & 6 & 7 & 6 & 4 & 5 & 6 & 6 & 4 & 5 & 6 \\
\hline & 0.8 & $\mathrm{~L}$ & 7 & 5 & 6 & 7 & 5 & 5 & 5 & 5 & 5 & 5 & 5 & 5 \\
\hline \multirow{2}{*}{13} & 1 & $\mathrm{R}$ & 6 & 6 & 4 & 2 & 0 & 0 & 0 & 0 & 0 & 0 & 0 & 0 \\
\hline & 1 & $\mathrm{~L}$ & 6 & 4 & 3 & 3 & 3 & 0 & 0 & 0 & 3 & 0 & 0 & 0 \\
\hline \multirow{2}{*}{14} & 0.9 & $\mathrm{R}$ & 4 & 4 & 3 & 4 & 4 & 4 & 3 & 0 & 4 & 4 & 3 & 0 \\
\hline & 0.9 & $\mathrm{~L}$ & 3 & 4 & 3 & 3 & 5 & 5 & 4 & 4 & 5 & 5 & 4 & 4 \\
\hline
\end{tabular}

Table 3

Difference Between Scores With and Without Glare for All Participants, Both Eyes (Right and Left, R-L)

\begin{tabular}{|c|c|c|c|c|c|c|c|c|c|c|c|c|c|c|c|c|c|c|c|c|c|c|c|c|c|c|c|c|}
\hline & \multicolumn{28}{|c|}{ Difference } \\
\hline & $1 \mathrm{R}$ & $1 \mathrm{~L}$ & $2 \mathrm{R}$ & $2 \mathrm{~L}$ & $3 R$ & $3 \mathrm{~L}$ & $4 \mathrm{R}$ & $4 \mathrm{~L}$ & $5 \mathrm{R}$ & $5 \mathrm{~L}$ & $6 \mathrm{R}$ & $6 \mathrm{~L}$ & $7 \mathrm{R}$ & $7 \mathrm{~L}$ & $8 \mathrm{R}$ & $8 \mathrm{~L}$ & 9R & 9L & $\begin{array}{l}10 \\
\mathrm{R}\end{array}$ & $\begin{array}{l}10 \\
\mathrm{~L}\end{array}$ & $\begin{array}{l}11 \\
\mathrm{R}\end{array}$ & $\begin{array}{l}11 \\
\mathrm{~L}\end{array}$ & $\begin{array}{l}12 \\
\mathrm{R}\end{array}$ & $\begin{array}{l}12 \\
\mathrm{~L}\end{array}$ & $\begin{array}{l}13 \\
\mathrm{R}\end{array}$ & $\begin{array}{l}13 \\
\mathrm{~L}\end{array}$ & $\begin{array}{l}14 \\
\mathrm{R}\end{array}$ & $\begin{array}{l}14 \\
\mathrm{~L}\end{array}$ \\
\hline 3 & 1 & 2 & -1 & 0 & 5 & 2 & 3 & 0 & 0 & 1 & 0 & 1 & 1 & 0 & 1 & -1 & 0 & 0 & 2 & 2 & 0 & -1 & 0 & 2 & 6 & 3 & 0 & -2 \\
\hline 6 & 2 & 1 & -1 & 1 & 1 & 1 & 0 & 1 & 0 & 0 & 1 & -2 & 0 & 0 & 1 & 0 & -1 & 0 & 2 & 2 & 2 & 3 & 1 & 0 & 6 & 4 & 0 & -1 \\
\hline 12 & 1 & 1 & 3 & 0 & 1 & 0 & 0 & -1 & 4 & 0 & 1 & 0 & 1 & 0 & -1 & 0 & -1 & -1 & 1 & 1 & -1 & 2 & 1 & 1 & 4 & 3 & 0 & -1 \\
\hline 18 & 1 & 0 & -1 & 0 & 0 & 0 & 0 & 0 & 1 & 0 & 0 & 0 & 1 & 1 & 0 & -1 & 1 & -2 & 2 & 0 & -1 & 0 & 1 & 2 & 2 & 3 & 4 & -1 \\
\hline
\end{tabular}


Table 4 shows the scores of depression estimated by means of BDI II, which suggest the following cutoff scores for diagnosing major depression: 0-13 Minimum; 14-19 Mild; 20-28 Moderate; 29-63 Severe. Nevertheless, since in this study we are dealing with a non-clinical population, the interval was set at 0-13 for "No depression" and 14-28 for "Depression".

Table 4

Total Score of Depression at Three Occasions, Age, and Sex of Participants

\begin{tabular}{|c|c|c|c|c|c|}
\hline Participant & Winter 1 & Winter 2 & Summer 1 & Age & Sex \\
\hline 1 & 1 & 6 & 5 & 34 & $\mathrm{M}$ \\
\hline 2 & 3 & 2 & 5 & 56 & $\mathrm{~F}$ \\
\hline 3 & 20 & 27 & 10 & 25 & F \\
\hline 4 & 2 & 0 & 0 & 50 & $\mathrm{~F}$ \\
\hline 5 & 4 & 0 & 0 & 38 & $\mathrm{~F}$ \\
\hline 6 & 5 & 18 & 1 & 35 & $\mathrm{~F}$ \\
\hline 7 & 13 & 11 & 8 & 31 & $\mathrm{~F}$ \\
\hline 8 & 22 & 18 & 19 & 29 & $\mathrm{~F}$ \\
\hline 9 & 8 & 8 & 15 & 22 & M \\
\hline 10 & 5 & 13 & 9 & 33 & M \\
\hline 11 & 4 & 4 & 0 & 50 & $\mathrm{~F}$ \\
\hline 12 & 1 & 10 & 0 & 25 & M \\
\hline 13 & 12 & 7 & 6 & 47 & M \\
\hline 14 & 15 & 12 & 10 & 49 & M \\
\hline
\end{tabular}

Table 5 shows the frequencies on the three indices of depression, melatonin, and glare sensitivity.

Table 5

Description (Frequencies) of the Three Indices $(N=14)$

\begin{tabular}{|c|c|c|c|c|c|}
\hline Indices & Depression & Melatonin & Glare & Age & Sex \\
\hline No depression & 12 & & & & \\
\hline Depression & 5 & & & & \\
\hline High producer & & 8 & & & \\
\hline Low producer & & 6 & & & \\
\hline No Glare & & & 10 & & \\
\hline Glare & & & 4 & & \\
\hline Older & & & & 8 & \\
\hline Younger & & & & 6 & \\
\hline Male & & & & & 6 \\
\hline Female & & & & & 8 \\
\hline
\end{tabular}

Significant correlations were found for the raw data of age and winter depression as well as between melatonin secretion in winter and sensitivity to glare (see Table 6).

A significant correlation was also found between the melatonin production index and age (see Table 7). 
Table 6

Correlations Between Raw Data of Depression and Melatonin Production During Winter and Summer Over Two Consecutive Years, Contrast Sensitivity Function Scores With and Without Glare, and Age $(N=14)$

\begin{tabular}{|c|c|c|c|c|c|c|c|c|}
\hline & DepWinter 1 & DepWinter 2 & DepSummer 1 & MelSummer & MelWinter & No glare & Glare & Age \\
\hline \multicolumn{9}{|l|}{ Kendall's tau } \\
\hline DepWinter1 & & $0.497^{*}$ & $0.644^{* *}$ & 0.246 & 0.011 & -0.116 & -0.150 & -0.236 \\
\hline DepWinter2 & $0.497^{*}$ & & $0.535^{*}$ & 0.367 & 0.291 & 0.264 & 0.184 & $-0.402^{*}$ \\
\hline DepSummer1 & $0.644^{* *}$ & $0.535^{*}$ & & 0.265 & 0.185 & 0.131 & 0.143 & -0.393 \\
\hline MelSummer & 0.246 & 0.367 & 0.265 & & $0.508^{*}$ & 0.193 & 0.239 & -0.155 \\
\hline MelWinter & 0.011 & 0.291 & 0.185 & $0.508^{*}$ & & 0.286 & $0.457^{*}$ & -0.233 \\
\hline No glare & -0.116 & 0.264 & 0.131 & 0.193 & 0.286 & & $0.800^{* *}$ & -0.320 \\
\hline Glare & -0.150 & 0.184 & 0.143 & 0.239 & $0.457^{*}$ & $0.800^{* *}$ & & -0.183 \\
\hline Age & -0.236 & $-0.402^{*}$ & -0.393 & -0.155 & -0.233 & -0.320 & -0.183 & \\
\hline \multicolumn{9}{|l|}{ Spearman's rho } \\
\hline DepreWinter 1 & & $0.681^{* *}$ & $0.800^{* *}$ & 0.276 & 0.006 & -0.163 & -0.184 & -0.312 \\
\hline DepreWinter 2 & $0.681^{* *}$ & & $0.650^{*}$ & 0.489 & 0.400 & 0.387 & 0.257 & $-0.591^{*}$ \\
\hline DepreSummer 1 & $0.800^{* *}$ & $0.650^{*}$ & & 0.359 & 0.281 & 0.144 & 0.143 & -0.493 \\
\hline MelSummer & 0.276 & 0.489 & 0.359 & & $0.572^{*}$ & 0.279 & 0.339 & -0.216 \\
\hline MelWinter & 0.006 & 0.400 & 0.281 & $0.572^{*}$ & & 0.490 & $0.620^{*}$ & -0.390 \\
\hline NoGlare & -0.163 & 0.387 & 0.144 & 0.279 & 0.490 & & $0.915^{* *}$ & -0.445 \\
\hline Glare & -0.184 & 0.257 & 0.143 & 0.339 & $0.620^{*}$ & $0.915^{* *}$ & & -0.261 \\
\hline Age & -0.312 & $-0.591\left(^{*}\right)$ & -0.493 & -0.216 & -0.390 & -0.445 & -0.261 & \\
\hline
\end{tabular}

Note. ${ }^{* *} p<0.01,{ }^{*} p<0.05$ (bilateral).

Table 7

Correlationes (Spearman's rho) Between the Three Indices, Sex, and Age $(N=14)$

\begin{tabular}{lllllll}
\hline & Depression & Melatonin & Glare & Sex & Age \\
\hline \multirow{5}{*}{ Kendall's tau } & Depression & & -0.344 & 0.189 & 0.043 & -0.346 \\
& Melatonin & -0.344 & & 0.091 & 0.167 & $0.487^{*}$ \\
& Glare & 0.189 & 0.091 & & -0.411 & 0.167 \\
& Sex & 0.043 & 0.167 & -0.411 & & 0.228 \\
& Age & -0.346 & $0.487^{*}$ & 0.167 & 0.228 & -0.407 \\
Spearman's rho & Gepression & -0.344 & 0.189 & 0.043 & $0.574^{*}$ \\
& Melatonin & -0.344 & & 0.091 & 0.167 & 0.196 \\
& Slare & 0.189 & 0.091 & & -0.411 & 0.269 \\
& Age & 0.043 & 0.167 & -0.411 & & 0.269 \\
\hline
\end{tabular}

Note. ${ }^{* *} p<0.01,{ }^{*} p<0.05$ (bilateral).

\section{Discussion}

The aim of this study at the first stage was to investigate in what extent melatonin production and glare sensitivity may be related and together contribute to symptoms of depression in non-clinical individuals. In spite of the small size of the sample, significant correlations were found between winter depression and melatonin production with age, as well as with sensitivity to glare. 
The evidence showed that deficiencies on the daily and seasonal pattern of melatonin secretion (being expected higher values during night and winter) seem to be one of the main causes of mood disorders. Females experience greater seasonal changes in mood and behavior than males, and older individuals experience less seasonal change than younger individuals (Morita, 2011; Wade et al., 2010; Tonello, 2008; Wetterberg et al., 1999a, 1999b).

The present correlational study investigated possible associations between these visual (glare) and non visual (melatonin secretion) factors in order to contribute in the elucidation of light as mood inducer in non clinical populations. Basically, these measurements revealed higher values of melatonin secretion in summer than in winter in general and eight high producers, five cases of depression sometime of the year, and four persons sensitive to glare, from a sample of 14 healthy individuals.

In line with previous research, the analysis of the data showed a significant and inverse correlation between age and winter depression: more winter depression in young people (below 35 years old) or less winter depression in older ones. But age also significantly correlated with the index of melatonin; higher melatonin production in individuals over the age of 35 (it should be noted that none individual in this sample exceeded 60 years).

Another significant and positive correlation was found between sensitivity to glare and winter melatonin production: the greater the sensitivity to glare, the greater the secretion of melatonin in winter, and this is an unexpected finding which deserves more attention.

In spite we fail to confirm the hypothesized pattern: subjects with sensitivity to glare and low nightly melatonin production will experience more symptoms of depression, glare was not investigated from this approach so far. Turner et al. (2009) showed that a decreased circadian photoreception by $50 \%$ combined with typical patterns of reduced bright light exposure may explain why significantly reduced melatonin amplitudes have been found by the fourth decade in some individuals. He also demonstrated that age-related crystalline lens yellowing reduced ocular transmission of the blue wave lengths optimal for circadian photoreception to levels ineffective for non-visual photoreception, not solved by cataract surgery. The susceptibility to glare increases with advancing years (Schieber, 1992), and the higher the exposure to optical radiation during the day, the lower the human circadian system's sensitivity becomes optical radiation at night (Wong, Dunn, \& Berson, 2005).

From the field of clinical psychology, it was demonstrated that low melatonin and elevated cortisol levels have typically been reported during depression (Lewy, 1985; Kennedy et al., 1998), and research on SAD, a depression with a seasonal pattern attributed mostly to the shorter winter photo period, suggested that the susceptibility to winter depression may arise not from behaviourally-related lack of sufficient light exposure, but an increased vulnerability to the amount of light received. SAD sufferers may require higher light exposure in summer and light therapy in winter to remain euthymic (Graw et al., 1999). Specifically, a study carried out in the same place of the present report (northern Argentina) showed that sadness was reported in a consistent way by half of the individuals in the sample, and the winter variety was the most common (22\%) followed by the summer variety (10\%) (Tonello, 2001; Küller, Ballal, Laike, Mikellides, \& Tonello, 2006).

Research in photobiology has revealed links between light and human health that are likely to have a significant effect on lighting practice (Van Bommel, 2005). In conclusion, in spite of the small size of the sample, the significant correlations found in this study, between winter depression, melatonin production, age, and sensitivity to glare, claim for more investigation in order to specify lighting design features for certain 
population, since it was demonstrated that lighting, as an environmental stressor, may trigger mental symptoms in individuals exhibiting super sensitivity to light. According to Stephenson et al. (2012), future research should include a translational approach from animal to human research, including healthy subjects and depressed patients, in order to determine, among others, the direct effects of light on sleep and alertness in humans and their subsequent impact on mood, and the potential applications in the field of societal lighting conditions.

\section{References}

Abrohomsson, M., \& Sjosrrand, J. (1986). Impairment of contrast sensitivity function (CSF) as a measure of disability glare. Investigative Ophthalmology \& Visual Science, 27, 1131-1136.

Beck, A., Steer, R., \& Brown, G. (2006). BDI-II inventario de depresión de beck. Manual: Segunda Edición, Paidós (Buenos Aires, Barcelona, México).

Berson, D., Dunn, F., \& Takao, M. (2002). Phototransduction by retinal ganglion cells that set the circadian clock. Science, 295, 1070 .

Bommel, W. V. (2005). Visual, biological, and emotional aspects of lighting: Recent new findings and their meaning for lighting practice. Leukos, 2(1), 7-11.

Boxer Wachler, B. S., \& Krueger, R. R. (1998). Normalized contrast sensitivity values. J. Refract Surg., 14, 463-466.

Boyce Peter, R. (2003). Human factors in lighting (2nd ed.). Taylor \& Francis.

Boyce Peter, R. (2011). Lemmings, light, and health revisited. Leukos, 8(2), 83-92.

Brainard, G., Hanifin, J., Greeson, J., Byrne, B., \& Glickman, G. (2001). Action spectrum for melatonin regulation in humans: Evidence for a novel circadian photoreceptor. The Journal of Neuroscience, 21(16), 6405-6412.

Brainard, G. C., Sliney, D., Hanifin, J. P., Glickman, G., Byrne, B., Greeson, J., \& Rollag, M. D. (2008). Sensitivity of the human circadian system to short wave-length (420 nm) light. J. Biol. Rhythms, 23(5), 379-86.

DiLaura, D. L., Houser, K. W., Mistrick, R. G., \& Steffy, G. R. (2011). The lighting handbook: Reference and application (10th ed.). New York (NY): Illuminating Engineering Society.

Fideleff, H., Boquete, H., Fideleff, G., Albornoz, L., Pérez Lloret, S., Suarez, M., Esquifino, A., Honfi, M., \& Cardinali, D. (2006). Gender-related differences in urinary 6-sulfatoxymelatonin levels in obese pubertal individuals. J. Pineal Res., 40, $214-218$.

Flynn-Evans, E., Tabandeh, H., Skene, D., \& Lockley, S. (2014). Circadian rhythm disorders and melatonin production in 127 blind women with and without light perception. J. Biol Rhythms, 29, 215.

Franssen, L., Coppens, J. E., \& Van den Berg, T. J. T. P. (2006). Compensation comparison method for assessment of retinal straylight. Investigative Ophthalmology \& Visual Science, 47, 768-776.

Graw, P., Recker, S., Sand, L., Kräuchi, K., \& Wirz-Justice, A. (1999). Winter and summer outdoor light exposure in women with and without seasonal affective disorder. Journal of Affective Disorders, 56, 163-169.

Harris, S., \& Dawson- Hughes, B. (1993). Seasonal mood changes in 250 normal women. Psychiatry Research, 49, 77-87.

Kennedy, S. H., Tighe, S., McVey, G., \& Brown, G. M. (1998). Melatonin and cortisol "switches" during mania, depression, and euthymia in a drug-free bipolar patient. Am. J. Psychiatry, 155(8), 1119-1121.

Küller, R., Ballal, S., Laike, T., Mikellides, B., \& Tonello, G. (2006). The impact of light and colour on psychological mood: A cross-cultural study of indoor work environments. Ergonomics, 49(14), 1496-1507.

Leger, D., Laudon, M., \& Zisapel, N. (2004). Nocturnal 6-Sulfatoxymelatonin excretion in insomnia and its relation to the response to melatonin replacement therapy. Am. J. Med., 116, 91-95.

Lewy, A. J., Wehr, T. A., Goodwin, F. K., Newsome, D. A., \& Rosenthal, N. E. (1981). Manic depressive patients may be supersensitive to light. The Lancet, I, 383-384.

Lewy, A. J., Sack, R. A., \& Singer, C. L. (1985). Bright light, melatonin and biological rhythms: Implications for the affective disorders. Psychopharmacology Bull., 21(3), 368-372.

Lewy, A. J., Sack, R. L., Singer, C. M., White, D. M., \& Hoban, T. (1988). Winter depression and the phase shift hypothesis for bright lights therapeutic effects: History, theory and experimental evidence. Journal of Biological Rhythms, 3, 121-134.

Morita, T. (2011). Decreased light transmittance because of aging and melatonin. In Ronald Ross Watson (Ed.), Melatonin in the promotion of health (2nd ed., pp. 375-378).

Münch, M., Knoblauch, V., Blatter, K., Schröder, C., Schnitzler, C., Kräuchi, K., Wirz-Justice, A., \& Cajochen, C. H. (2005). Age-related attenuation of the evening circadian arousal signal in humans. Neurobiology of Aging, 26, 1307-1319. 
Provencio, I., Rodriguez, I. R., Jiang, G., Hayes, W. P., Moreira, E. F., \& Rollag M. D. (2000). A novel human opsin in the inner retina. Journal of Neuroscience, 20(2), 600-605.

Provencio, I., Rollag, M., \& Castrucci, A. M. (2002). Photoreceptive net in the mammalian retina. Nature, 415, 493.

Rea, M. S. (2000). Lighting handbook: Reference and application (9th ed). New York: Illuminating Engineering Society of North America.

Rijn van, L. J., Nischler, C., Gamer, D., Franssen, L., Wit de, G. C., Coppens, J. E., Kaper, R., Vonhof, D., Grabner, G., Wilhelm, H., Völker-Dieben, H. J., \& Berg van den, T. J. T. P. (2000). Clinical studies on straylight and glare. Measurement of stray light and glare: Comparison of nyktotest, mesotest, stray light meter, and computer implemented stray light meter (Report of the European Glare Project). European Union.

Schieber, F. (1992). Aging and the senses. In J. E. Birren, R. B. Sloan, \& G. Cohen (Eds.), Handbook of mental health and aging (pp. 251-306). New York: Academic Press.

Srinivasan, V., Smits, M., Spence, W., Lowe, A. D., Kayumov, L., Pandi-Perumal, S. R., Perry, B., \& Cardinali, D. P. (2006). Melatonin in mood disorders. World J. Biol. Psychiatry, 7(3), 138-151.

Stephenson, K., Schroder, C., Bertschy, G., \& Bourgin, P. (2012). Complex interaction of circadian and non-circadian effects of light on mood: Shedding new light on an old story. Sleep Medicine Reviews, 16, 445-454.

Stone, P. T. (1999). The effects of environmental illumination on melatonin, bodily rhythms and mood states: A review. Lighting Research and Technology, 31(3), 71-79.

Tonello, G. (2001). Lighting, mood and seasonal fatigue in northern Argentina: Comparison to countries close to and further from the equator (Doctoral thesis, Editorial Studentlitteratur, Lund. ISBN 91-628-4900-X).

Tonello, G. (2008). Seasonal affective disorder: Lighting research and environmental psychology. Lighting Research and Technology, 40(2), 103-110.

Turner, P., Van Someren, E., \& Mainster, M. (2009). The role of environmental light in sleep and health: Effects of ocular aging and cataract surgery. Sleep Medicine Reviews. doi:10.1016/j.smrv.2009.11.002

Wade, A., Ford, I., Crawford, G., McConnachie, A., Nir., T., Laudon, M., \& Zisapel, N. (2010). Nightly treatment of primary insomnia with prolonged release melatonin for 6 months: A randomized placebo controlled trial on age and endogenous melatonin as predictors of efficacy and safety. BMC Medicine, 8, 51. Retrieved from http://www.biomedcentral.com/1741-7015/8/51

Wetterberg, L., Bergiannaki, J., Paparrigopoulos, T., Von Knorring, L., Eberhard, G., Bratlid, T., \& Yuwiler, A. (1999a). Normative melatonin excretion: A multinational study. Psychoneuroendocrinology, 24(2), 209-226.

Wetterberg, L., Bratlid, T., Von Knorring, L., Eberhard, G., \& Yuwiler, A. (1999b). A multinational study of the relationships between nighttime urinary melatonin production, age, gender, body size, and latitude. Eur Arch Psychiatry Clin Neurosci, 249, 256-262.

Wong, K. Y., Dunn, F. A., \& Berson, D. M. (2005). Photoreceptor adaptation in intrinsically photosensitive retinal ganglion cells. Neuron, 48(6), 1001-1010. 